\title{
EL ONFALOCELE EN NUESTRO MEDIO
}

\author{
Doctores Jorge Milanés P., Alberto Zabaleta L.
}

De todas las regiones del recién nacido, la que primero y principalmente llama la atención es indudablemente la región umbilical. De ahí que cualquier anomalía en este sitio sea reconocida de inmediato por quien está asistiendo el parto. En los casos que lo requieran, la terapéutica no debe hacerse esperar, ya que cualquier demora o tratamiento inadecuado repercutirá desfavorablemente sobre el porvenir del recién nacido.

De acuerdo con los resultados obtenidos por nosotros, cuanto antes se aplique el tratamiento indicado - cirugía- mejores han sido los resultados.

El reconocimiento de esta anomalía somática en el feto, que no es más que la persistencia de una etapa normal de la vida embrionaria, es por demás asaz fácil.

\section{Definición}

El onfalocele es un defecto congénito de la pared abdominal en la base de implantación del cordón umbilical, a nivel de la cual, la piel y demás es- tructuras son reemplazadas en una extensión mayor o menor, por el amnios y a través del cual puede observarse el contenido de la hernia. Puede ser de forma plana o semejar una tumoración cilindroidea; lleno las más de las veces por asas intestinales o bien por otras vísceras.

\section{Sinónimo}

Exónfalos. Hernia Amniótica. Amniocele. Hernia Funicular. Ectopia Viscerum.

\section{Incidencia}

Lo llamativo de la lesión y la simplicidad del diagnóstico, hace que los datos estadísticos sean bastante exactos. En relación a nuestro medio, podemos decir que el onfalocele es muy escaso. Se pasan en más de las ocasiones muchos años sin ver uno. Sin embargo, en nuestra casuística de solo 6 casos, 3 ocurrieron en el año de 1962 y los otros 3 en lo que va corrido del presente año. Las estadísticas norteamericanas dan un caso por cada 10.000 recién nacidos.

\footnotetext{
* Departamento de Obstetricia y Ginecología. Facultad de Medicina. Universidad de Cartagena.
} 


\section{Material}

Se trata de 6 casos de onfalocele ocurridos en fetos de sexo masculino, el peso de los cuales osciló entre 3.200 y 3.700 gramos y sin ninguna otra anomalía. Todos fueron tratados quirúrgicamente, 5 durante las tres primeras horas de vida y el sexto durante las primeras 18 horas, por cuanto su nacimiento tuvo lugar fuera del servicio hospitalario. El contenido de la hernia to componía asas intestinales en cuatro de los casos, en los dos restantes el hígado; en uno casi todo el órgano $y$ en el otro un segmento en forma de pirámide que hubo que extirpar por las. adherencias que tenía contraídas con la bolsa herniaria.

\section{Anestesia}

Se utilizó el seconal a dosis de 10 centígramos en 20 c. c. de vehículo acuoso por vía rectal y a medida de las necesidades del acto operátorio. Además, xilocaína infiltrada localmente al rededor del saco de la hernia. En un caso ciclopropano.

\section{Tratamiento}

Ya no hay discusión entre jareta y - extirpación quirúrgica de la herñia; siendo esta llevada a cabo de inmediato. En el preoperatorio lo único que hicimos, después de seccionado el funículo, fue cubrir la región con una gasa estéril húmeda.

Exéresis total del saco amniótico a tres milímetros por debajo del borde de implantación. Abierta la cavidad abdominal, revisión de la misma. En todos los casos extirpamos el apéndice cecal. El cierre de la pared se hizo en uno o dos planos con seda número 40 y como único apósito una gasa embebida en alcohol. En el post. operatorio: antibióticos. Largactil : 3 gotas cada 8 horas durante 48 horas. A las 12 horas de operados, en caso que quisieran succionar, se les daba dextrosa. A las 48 horas se les iniciaba la alimentación materna.

\section{Resumen}

Presentamos 6 casos de onfalocele ocurridos en recién nacidos de sexo masculino y tratados quirúrgicamente mediante la extirpación total de la bolsa herniaria dentro de las 3 primeras horas de vida en 5 casos. En todos ha habido buenos resultados hasta el presente. Se hizo en los 6 casos apendicectomía.

\section{BIBLIOGRAFIA}

Cresson L., PIlling G. P.: Pediatric clinies of North Ameriea. Vol. 6. Ne 4, págs. 1.101 y sigs. Nov. 1959.

HALCOMB G. W. Jr.: Amer. J. of surg. Vol. 101. Na 5, págs. 589 y sigs. Mayo 1961. Obstetric. Greenhill. XI ed. inglesa. Pág. 586. 1957. 